\title{
CALCIUM BINDING PROPERTIES OF RAT HEART PLASMA MEMBRANE AND INHIBITION BY STRUCTURAL ANALOGUES OF $d l$-PROPRANOLOL*
}

\author{
Douglas A. Feldman and Paul A. Weinhold \\ Veterans Administration Hospital and Department of Biological Chemistry, University \\ of Michigan, Ann Arbor, MI 48105, U.S.A.
}

(Received 29 November 1976; accepted 4 March 1977)

\begin{abstract}
The isolation and characterization of a plasma membrane preparation from rat heart is described. Enzymatic, chemical, and electron microscopic analysis revealed a relative lack of contamination with nuclear, mitochondrial, ribosomal, and sarcoplasmic reticulum membrane. One calcium binding site $\left(K_{d}=265 \mu \mathrm{M}, B_{\max }=65 \mathrm{nmoles} / \mathrm{mg}\right.$ protein) was detected by equilibrium dialysis. Monovalent metal ions exhibited 10-100-fold less inhibition potency than divalent metal ions when analyzed by competitive inhibition of calcium binding. The range of $K_{i}$ values found for divalent metal ions was similar to the $K_{d}$ value for calcium. $\mathrm{La}^{+3}$ produced a potent non-competitive inhibition. A large variety of structural analogues of $d, l$-propranolol, many of which have been shown to lack $\beta$-adrenergic blocking activity, were competitive inhibitors of the calcium binding activity, with $K_{i}$ values ranging from $40-900 \mu \mathrm{M}$. Electrophilic, hydrophobic, and diamino substituents greatly increased the inhibitory activity. There was no significant difference between related tertiary and quaternary amines. The experimental antiarrhythmic agent UM 272 had the least ability to inhibit calcium binding to the cardiac plasma membrane preparation $\left(K_{i}=795 \mu \mathrm{M}\right)$. However, UM 424, another experimental antiarrhythmic agent, had an inhibitory activity similar to $d /$-propranolol $\left(K_{i}=115 \mu \mathrm{M}\right.$ and $108 \mu \mathrm{M}$, respectively).
\end{abstract}

There has been a considerable amount of speculation about the identity and location of the intracellular membrane storage sites which serve to release large amounts of calcium into the cytoplasm immediately after the depolarization of the cardiac plasma membrane (sarcolemma). G. A. Langer $[1,2]$ has postulated that subsarcolemma stores of calcium serve as the rapid release sites which contribute to the pool of "contractile dependent" calcium. This intermediate region of calcium binding sites, which may include the external lamina and $T$ tubule membrane systems, would be in rapid equilibrium with the pool of extracellular calcium. Calcium release could be triggered by the increased influx of extracellular sodium or calcium ions which occurs during and immediately after the membrane depolarization event. Calcium would be transferred into the cytoplasm, to activate myofibril contraction, by a proposed electroneutral calcium exchange process.

The proposed role of the cardiac plasma membrane as an ion exchange region of the cell has received additional attention in pharmacological research designed to determine the mechanism of action of membrane active drugs, including local anesthetics, $\beta$-adrenergic antagonists and antiarrhythmic agents [3]. Local anesthetic agents interfere with membrane depolarization by displacement of calcium from

* This work was supported by the Medical Research Service of the Veterans Administration and by Grant HL1 5766 from the National Heart and Lung Institute. anionic binding sites on the cell membrane [4]. $\beta$-Adrenergic antagonists, such as $d l$-propranolol, have been found to significantly decrease calcium accumulation into sarcoplasmic reticulum [5]. The ability of antiarrhythmic agents to prolong the atrioventricular electrical conduction time and prolong the effective refractory period may be related to decreases in sodium and potassium conductance across the plasma membrane [6-8]. The effects of these compounds on calcium conductance are unknown. Madeira et al. [9] have previously demonstrated the ability of selected local anesthetic agents to competitively inhibit calcium binding to rabbit skeletal muscle plasma membrane. However, a critical evaluation and comparison of the ability of the various types of membrane-active organic amines, to inhibit calcium binding to purified preparations of cardiac plasma membrane, has not been previously presented. Furthermore, the recent development of a new category of antiarrhythmic agents by Lucchesi and coworkers [6-8], which do not exhibit local anesthetic or $\beta$-adrenergic antagonist activity, provide a unique opportunity to determine if the action of these compounds includes a direct effect on calcium ion metabolism in cardiac plasma membrane.

This communication will describe the isolation of a preparation of rat heart plasma membrane, using relatively mild, low ionic strength buffer conditions. A comparison of the ability of a wide variety of structural analogues of $d i$-propranolol to inhibit the calcium binding activity of the plasma membrane preparation will be presented. 


\section{MATERIALS AND METHODS}

Female rats $(180-250 \mathrm{~g})$ were obtained from Holtzman Co., Madison. WI. $\left[{ }^{45} \mathrm{Ca}\right]$ calcium chloride was purchased from New England Nuclear Corp. $(400 \mathrm{Ci} /$ mole). The experimental antiarrhythmic and anesthetic drugs were synthesized in the laboratory of Dr. R. E. Counsell. Department of Medicinal Chemistry, University of Michigan. Each compound was prepared as the iodide or chloride salt, in a racemic mixture of the $d l$ isomers. The chemical structures were verified by nuclear magnetic resonance and infrared analysis (R. E. Counsell, personal communication). Quinidine $\mathrm{HCl}$, procaine $\mathrm{HCl}$, tetracaine $\mathrm{HCl}, \mathrm{dl}$-propranolol, ouabain, and carbamylcholine were purchased from Sigma Chemical $\mathrm{Co}$. Dibucaine $\mathrm{HCl}$ was obtained from K \& K Laboratories. Plainview, NY. Lanthanum chloride was obtained from $\Lambda$ pache Chemicals, Rockford, IL. All other biochemicals were purchased from Sigma Chemical Co.

Isolation of plasma membranes. The method for isolation of rat heart plasma membranes were based on procedures described by Carvalho et al. [10], Rosenthal et al. [11] and Zacks et al. $[12,13]$. Freshly excised rat (female) hearts were rinsed and minced in homogenization buffer containing $50 \mathrm{mM} \mathrm{CaCl}$, $10 \mathrm{mM}$ histidine-Tris- $\mathrm{HCl}$ at $\mathrm{pH} \mathrm{7.6}$. The tissue was homogenized for $45 \mathrm{sec}$ in a Brinkmann Polytron (PCV-2) set at speed 4.5. The homogenate wass filtered through a stainless stcel screen (406 micron mesh), and the filtrate was allowed to stand for $1 \mathrm{hr}$ at 4 . The mixture was centrifuged for $1 \mathrm{~min}$ at $272 \mathrm{~g}$. The pellet was resuspended in $10 \mathrm{mM}$ histidine-Tris$\mathrm{HCl} \mathrm{pH} 7.6$ with a motor driven teflon homogenizer and centrifuged as before. This process was repeated until the supernatant solution was colorless and free from protein. The membranes were resuspended in ice cold deionized water that was neutralized to $\mathrm{pH}$ 7.8 with a few grains of Tris. After $30 \mathrm{~min}$ at $4^{3}$ the membranes were collected by centrifugation for $5 \mathrm{~min}$ at $272 \mathrm{~g}$. The water treatment was repeated once. In some cases, the preparation was exposed to $10 \mathrm{mM}$ histidine-Tris- $\mathrm{HCl}$ pH 7.6 containing $1.2 \mathrm{M} \mathrm{KCl}$ for $10 \mathrm{~min}$ at $4^{\circ}$. The membranes were collected by centrifugation at $10.000 \mathrm{~g}$ for $30 \mathrm{~min}$ and resuspended in $10 \mathrm{mM}$ histidine-Tris- $\mathrm{HCl} \mathrm{pH} 7.6$ containing $0.25 \mathrm{M}$ sucrose. The membrane suspension was layered on top of a discontinuous sucrose gradient containing equal volumes of $0.3 \mathrm{M} / 1.32 \mathrm{M} / 1.75 \mathrm{M}$ sucrose. After centrifugation for $2 \mathrm{hr}$ at $76,400 \mathrm{~g}$ (Beckman SW 41 rotor), the plasma membrane fraction was collected at the $1.32 \mathrm{M} / 1.75 \mathrm{M}$ interface. The membranes were washed once and resuspended in $10 \mathrm{mM}$ histidineTris- $\mathrm{HCl} \mathrm{pH} 7.6$ containing $0.25 \mathrm{M}$ sucrose. Individual $0.5-1.0 \mathrm{ml}$ aliquots $(5-10 \mathrm{mg}$ protein $/ \mathrm{ml})$ were stored at $-40^{\circ}$ for periods up to 2 months.

General methods. Protein concentration was determined by the method of Lowry et al. [14] with bovine serum albumin as the reference standard. DNA was determined by the method of Richards [15] with salmon sperm DNA as the reference standard. Cholesterol was determined by the method of Kirkpatrick et al. [16]. Total membrane lipids were extracted according to the method of Folch et al. [17]. Lipid phosphorous was determined as described previously [18]. Succinate Dehydrogenase activity was measured according to Slater and Planterose [19], 5-AMP Nucleotidase activity was measured by the method of Heppel and Hilmore [20]. Mg-ATPase activity was measured in the presence of $5.0 \mathrm{mM} \mathrm{MgCl}, 5.0 \mathrm{mM}$ ATP, $0.1 \mathrm{mM}$ EGTA, $0.05^{\circ}$ sodium azide, and $25 \mathrm{mM}$ Tris-maleate buffer $\mathrm{pH} 6.7$. After incubation at $37^{\circ}$, the inorganic phosphate released was determined by the method of Sanui [21]. The calcium stimulated $\mathrm{Mg}$-ATPase was determined by adding $0.1 \mathrm{mM} \mathrm{CaCl}_{2}$ to the $\mathrm{Mg}$-ATPase incubation mixture. Ca-ATPase activity was measured in the presence of $5.0 \mathrm{mM} \mathrm{CaCl}, 5.0 \mathrm{mM}$ ATP, $0.05^{\circ}{ }_{0}$ sodium azide, and $25 \mathrm{mM}$ Tris-maleate buffer pH 6.7 .

Calcium binding and calcium uptake analysis by Millipore filtration. Calcium binding was measured by incubating plasma membranes for $5 \mathrm{~min}$ at $37^{\circ}$ in the presence of $0.1 \mathrm{mM}^{45} \mathrm{CaCl}_{2}$ (sp. act. $=10,000-15,000$ cpm/nmole), $5 \mathrm{mM}$ ATP. $5 \mathrm{mM} \mathrm{MgCl}, 0.05_{2}^{\circ}$ sodium azide, and $25 \mathrm{mM}$ Tris maleate buffer $\mathrm{pH} 6.5$. After the incubation, a $200 \mu$ aliquot was withdrawn and applied to a $25 \mathrm{~mm}$ diameter Millipore filter (Type GS, $0.22 \mu \mathrm{m}$ pore size). The filter was washed with $5.0 \mathrm{ml}$ ice-cold $25 \mathrm{mM}$ Tris maleate buffer ( $\mathrm{pH} 6.7$ ). The amount of ${ }^{45} \mathrm{Ca}$ retained by the membrane sample was measured by liquid scintillation in $10 \mathrm{ml}$ Aquasol (New England Nuclear). The amount of ${ }^{45} \mathrm{Ca}$ retained by filters without added membrane sample was equivalent to the instrumental background counting rate. Calcium uptake was measured by adding $5 \mathrm{mM}$ potassium oxalate to the calcium binding incubation mixture.

Calcium binding analysis by equilibrium dialysis. Calcium binding to plasma membranes in the absence of $\mathrm{MgATP}^{-2}$ was measured by equilibrium dialysis. using an 8 chamber dialysis block (Bel-Art Model 375 ), with $0.5 \mathrm{ml}$ volume per half chamber. One side of each chamber was filled with $0.3 \mathrm{ml}$ of $50 \mathrm{mM}$ Tris- $\mathrm{HCl} \mathrm{pH} 7.0$ containing $0.20 .4 \mathrm{mg}$ of plasma membrane protein. The opposite side of each dialysis chamber contained $0.3 \mathrm{ml}{ }^{45} \mathrm{CaCl}_{2}$ (sp. act. $=$ $10,000-15,000 \mathrm{cpm} / \mathrm{nmole}$ ) dissolved in deionized $\mathrm{H}_{2} \mathrm{O}$ at a concentration of $16,4-416 \mu \mathrm{M}$. In experiments designed to measure the ability of an inhibitor to prevent calcium binding, the agent was added to the $\mathrm{CaCl}_{2}$ side of the dialysis chamber at a final concentration of $0.1-1.0 \mathrm{mM}$. In all cases, the final volume of each dialysis chamber was $0.6 \mathrm{ml}$. The two halves of the dialysis block were separated by a single sheet of cellulose dialysis membrane ( $5 \times 5 \mathrm{~cm}$; Bel Art No. 299), previously soaked overnight in deionized water. Dialysis was performed by vertical rotation for $24 \mathrm{hr}$ at $4^{\circ}$ at a constant speed of 10 RPM (Scientific Industries Rotator, Model 150). Duplicate aliquots of $100 \mu \mathrm{l}$ were removed from each half chamber with a $100 \mu 1$ Eppendorf pipet and the amount of radioactivity was measured by liquid scintillation. Control experiments revealed that calcium equilibrium was established after $20 \mathrm{hr}$ at 4 Equivalent binding results could be obtained if ${ }^{45} \mathrm{Ca}$ was initially added to either half of a dialysis chamber. The average variance from true equilibrium was 4.8 per cent. In order to minimize the effect of this variability, the total concentration of protein and calcium were arranged so that the amount of calcium bound was $\geq 25$ per cent of the total calcium concentration. 
Calcium binding constants were determined according to Klotz et al. [22]. In this method the inverse amount of calcium bound to $1 \mathrm{mg}$ of plasma membrane protein was plotted versus the inverse concentration of unbound calcium in the equilibrated sample. Normally, 4-6 individual data points were used to construct a single plotted line. Each experimental plot of data points was considered acceptable if the linear correlation coefficient was greater than 0.95 , as calculated by the least squares method of linear analysis.

Calcium binding inhibition analysis was performed according to the slope-intercept method described by Dixon and Webb [23]. A competitive type of inhibition of calcium binding produces an apparent increase in the calcium dissociation constant. The inhibition constant ( $K_{i}$, competitive) can be calculated from the interception point of the plotted lines on the calcium concentration axis, according to the equation $K_{i}=[i] /\left[\left(K_{\text {app }} \div K_{d}\right)-1\right]$. In this case, the point of interception of the two lines (with and without added inhibitor) on the $1 / B$ axis must be identical. For the experiments described in this communication, the maximum acceptable deviation from a true interception of the least squares linear plots was \pm 10 per cent. A noncompetitive type of inhibition produces an apparent decrease in the maximum amount of calcium bound. The inhibition constant $\left(K_{i}\right.$, noncompetitive) can be calculated from the interception point of the plotted lines on the $1 / B$ axis, according to the equation $K_{i}=[i] /\left[\left(B_{\max } \div\right.\right.$ $\left.\left.B_{\text {app }}\right)-1\right]$. In this case, the maximum acceptable deviation from a true interception of the least squares linear plots on the calcium axis, was \pm 10 per cent.

Electron microscopy. Electron microscopy was performed by Dr. Sun-Kee Kim at the Veterans Administration Hospital, Ann Arbor, Michigan.

Plasma membrane was pelleted by centrifugation at $10,000 \mathrm{~g}$ for $30 \mathrm{~min}$ and fixed in $0.1 \mathrm{M}$ sodium phosphate buffer (pH 7.4) containing $1 \%$ paraformaldehyde and $1.4 \%$ glutaraldehyde. After several rinses with phosphate buffer and overnight storage in buffer containing $0.2 \mathrm{M}$ sucrose, the pellets were post-fixed in phosphate buffer containing $1 \%$ Osmium tetroxide for $1 \mathrm{hr}$ and then stained with $0.5 \%$ uranyl acetate according to Karnovsky [24]. The stained pellets were dehydrated and embedded in Epon as described by Luft [25]. Sections of 700A thickness were cut on a Porter-Blum (MT IIB) microtome and stained with uranyl acetate according to Venable and Coggeshall [26]. The sections were examined in a Hitachi IIC electron microscope operated at $75 \mathrm{KV}$.

\section{RESULTS}

\section{Properties of plasma membrane preparations}

Chemical and enzyme analysis. Approximately 20 per cent of the initial amount of protein in the homogenate was recovered in the plasma membrane preparation. Approximately 37 per cent of the initial amount of cholesterol was recovered with a cholesterol/phospholipid ratio of 0.33 , compared to a ratio of 0.25 in the homogenate. Less than 10 per cent of the initial activity of succinate dehydrogenase was recovered in the membrane preparation.

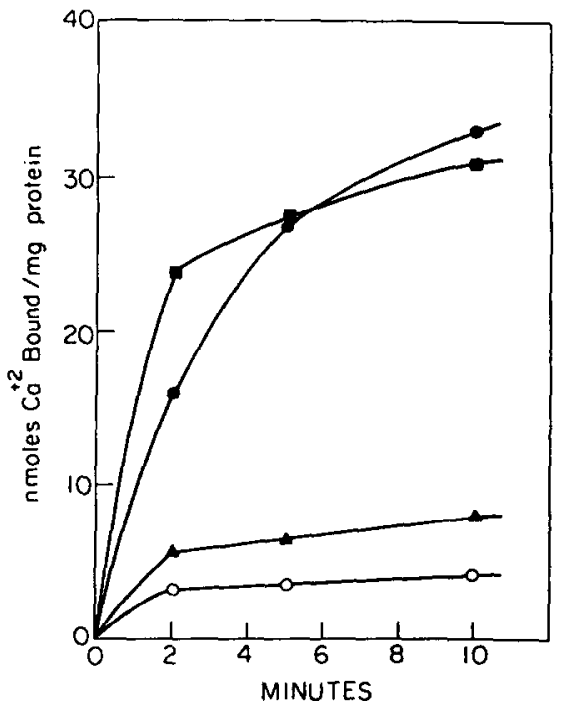

Fig. 1. Analysis of calcium binding and calcium transport in purified rat heart plasma membrane by Millipore filtration. Calcium binding and calcium transport activities were measured as described in Methods. Each incubation mixture contained $0.1 \mathrm{mM}{ }^{45} \mathrm{CaCl}_{2}$ (sp. act. $=10,000-15,000$ cpm/nmole), $0.64 \mathrm{mg}$ plasma membrane protein per $\mathrm{ml}$ of assay mixture, $25 \mathrm{mM}$ Tris-maleate buffer $\mathrm{pH} 6.7,0.05 \%$ sodium azide, and the following specific additions: Mg-ATP, $5 \mathrm{mM}$ and oxalate, $5 \mathrm{mM} \longrightarrow$ : oxalate, $5 \mathrm{mM}-\mathrm{Mg}$-ATP, $5 \mathrm{mM}-\mathrm{O}-\mathrm{O}-$; no addition, - - $\mathbf{A - \Lambda}-$.

However, 30 per cent of the initial 5'-AMP nucleotidase activity was recovered in the final preparation.

Calcium binding and transport activities of the plasma membrane preparation were not stimulated by $\mathrm{MgATP}^{-2}$ (Fig. 1). Furthermore, $\mathrm{MgATP}^{-2}$ caused a slight inhibition of calcium binding. Measurements of calcium transport in cardiac sarcoplasmic reticulum are typically performed only in the presence of $\operatorname{MgATP}^{-2}[27,28]$, as the rate of transport in the presence of oxalate, without $\mathrm{MgATP}^{-2}$ is minimal. This result has also been verified in our laboratory. Using a preparation of sarcoplasmic reticulum from dog heart [28], $\mathrm{MgATP}^{-2}$ produced a 7-fold stimulation of calcium binding (oxalate absent) and a 500-fold stimulation of calcium transport (oxalate present). These MgATP $^{-2}$ stimulated activities are well documented indicators of sarcoplasmic reticulum function $[27,28]$.

Measurements of the various plasma membrane ATPase activities are presented in Fig. 2. The addition of low concentrations of calcium produced a maximum 1.5-fold increase of the Mg-ATPase activity, an effect similar to that observed in preparations of sarcoplasmic reticulum [27]. This calcium stimulated, Mg-ATPase is thought to be specifically located in sarcoplasmic reticulum [29] and the enzyme activity reported by Sulakhe et al. [27] is 20 times greater than that observed with the plasma membrane preparation. The Ca-ATPase activity was 8 times more active than the Mg-ATPase activity; whereas, in sarcoplasmic reticulum membrane, the Ca-ATPase was less active than the Mg-ATPase [27]. The Ca-ATPase activity in plasma 


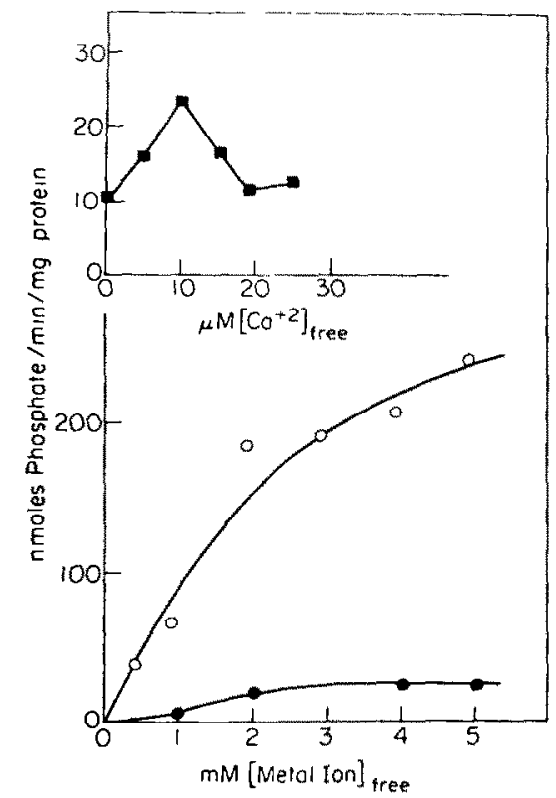

Fig. 2. Analysis of ATrase activities in rat heart plasma membranes. The ATPase activities were measured as described in Methods. Each incubation mixture contained $0.13 \mathrm{mg} / \mathrm{ml}$ plasma membrane protein. $25 \mathrm{mM}$ Trismaleate buffer $\mathrm{pH} 6.7,0.05^{\circ} \%$ sodium azide, $100 \mu \mathrm{M}$ ethyleneglycol-bis-( $\beta$-aminoethyl ether) $N, N^{*}$-tetraacetic acid (EGTA). and the following additions: $0-300 \mu \mathrm{M} \mathrm{CaCl}$, $1 \mathrm{mM} \mathrm{MgCl}$, and $1 \mathrm{mM}$ ATP (Calcium activated $\mathrm{Mg}$ ATPase) - - : $0-5 \mathrm{mM} \mathrm{MgCl}$ and $5 \mathrm{mM}$ ATP (MgATPase) $\longrightarrow 0-5 \mathrm{mM} \mathrm{CaCl}_{2}$ and $5 \mathrm{mM}$ ATP (CaATPase) - -0 . The concentration of calcium not complexed with EGTA ([Ca+2]free) was calculated according to Owen [41].

membrane is thought to be involved in promoting calcium transport across the cell membrane $[30,31]$

The results obtained from measurements of ATPase activities and calcium binding and uptake activities indicate that the plasma membrane preparation is relatively uncontaminated by sarcoplasmic reticulum membrane.

Electron microscopy. A careful analysis of a large series of individual photographs from an electron microscopic examination of the preparation indicated a relative absence of nuclei, mitochondria and rough endoplasmic reticulum. The presence of sarcoplasmic reticulum vesicles cannot be distinguished from plasma membrane vesicles by this technique. A significant amount of adsorbed contractile myofibrils was observed at lower magnification. A large number of cell junctions, or intercalated disks, were also observed in the preparation. Hui et al. [30] have recently described a procedure for isolating plasma membranes from guinea pig heart which includes extraction with $\mathrm{KCl}$. This treatment caused the disruption and removal of the adsorbed contractile proteins. When our plasma membrane preparation was extracted with $1.25 \mathrm{M} \mathrm{KCl}$ as described by Hui et al. [30], a significant amount of the adsorbed myofibrils were removed, as determined by electron microscopy. Zacks etal. [12] and Vandenburg et al. [13] have recommended against extraction with highly concentrated salt solutions, in order to avoid

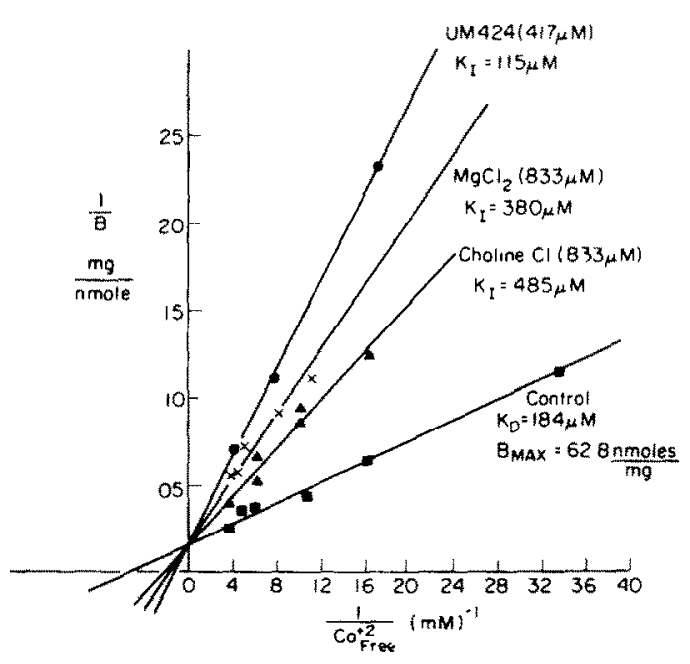

Fig. 3. Klotz plot analysis of calcium binding to rat heart plasma membranes measured by equilibrium dialysis. Calcium binding activity was measured by equilibrium dialysis, as described in Methods. The final plasma membrane protein concentration was $1.91 \mathrm{mg} / \mathrm{ml}$ on the sample side of the dialysis membrane.

removing the external lamina layer and loosely bound extrinsic proteins. In fact, Hui et al. [30] reported significant losses of $\mathrm{Na}^{+} \mathrm{K}^{+}$-ATPase activity $(78$ per cent), 5-Nucleotidase activity (76 per cent), and Adenylate Cyclase activity (45 per cent) after extraction with $1.2 \mathrm{M} \mathrm{KCl}$. For these reasons, we chose to omit the extraction process from our isolation procedure.

\section{Measurement of calcium binding}

Equilibrium dialysis was used to determine the extent of calcium binding to the plasma membrane preparation. In the calcium concentration range normally employed in these studies $(16-416 \mu \mathrm{M})$, only one type of calcium binding site could be detected (Fig. 3). From a series of 4 independent membrane preparations, the average calcium dissociation constant $\left(K_{d}\right)$ was $265 \pm 61 \mu \mathrm{M}$, and the average maximum calcium binding capacity $\left(B_{\max }\right)$ was $65 \pm 1.4 \mathrm{nmoles} / \mathrm{mg}$ protein. As plotted according to Klotz et al. [22], this result indicates that this class of calcium binding sites would be one-half saturated at a free calcium concentration of $0.26 \mathrm{mM}$. Therefore, this class of binding sites would be greater than 80 per cent saturated when exposed to $1.0 \mathrm{mM}$ $\mathrm{Ca}^{+2}$. the concentration normally found in extracellular fluids [32].

An analysis of calcium binding to a plasma membrane preparation treated with $1.25 \mathrm{M} \mathrm{KCl}$, according to Hui et al. [30] indicated that the binding capacity for calcium was 2.4 times greater than the binding capacity of plasma membrane prepared in the absence of $\mathrm{KCl}$. However, the $K_{d}$ values were similar in both preparations. Thus. the $\mathrm{KCl}$ treatment apparently removes protein material which does not significantly contribute to the calcium binding of the plasma membrane.

\section{Inhibition of calcium binding by other metal ions}

All of the divalent metal ions produced a competitive inhibition within a concentration range 
Table 1. Inhibition of calcium binding to rat heart plasma membranes*

\begin{tabular}{lc}
\hline Metal & $K_{l}(\mathrm{mM})$ \\
\hline $\mathrm{NaCl}$ & 33.5 \\
$\mathrm{KCl}$ & 7.56 \\
$\mathrm{LiCl}$ & 2.19 \\
$\mathrm{RbCl}$ & 5.08 \\
$\mathrm{MgCl}_{2}$ & 0.38 \\
$\mathrm{ZnCl}_{2}$ & 0.12 \\
$\mathrm{SrCl}_{2}$ & 0.31 \\
$\mathrm{BaCl}_{2}$ & 0.26 \\
$\mathrm{CoCl}_{2}$ & 0.23 \\
$\mathrm{MnCl}_{2}$ & 0.18 \\
$\mathrm{LaCl}_{3}$ & 0.09
\end{tabular}

* Calcium binding activity was measured as described in Methods. All inhibitors were competitive except $\mathrm{LaCl}_{3}$, which was noncompetitive. The dissociation constant $\left(K_{d}\right)$ for $\mathrm{CaCl}_{2}$ was $0.26 \pm 0.06 \mathrm{mM}$ ( 4 determinations). approximately equivalent to the dissociation constant of calcium (Table 1). Monovalent metal ions were considerably less active competitive inhibitors of calcium binding. Whereas $\mathrm{K}^{+}, \mathrm{Li}^{+}$, and $\mathrm{Rb}^{+}$ possessed approximately the same inhibitory activity, $\mathrm{Na}^{+}$was significantly less potent $\left(K_{i}=33.5\right)$. The trivalent metal ion, $\mathrm{La}^{+3}$, caused a potent noncompetitive inhibition of calcium binding. Langer [2] found that $\mathrm{La}^{+3}$ is an impermeable ion, yet it can specifically uncouple the cardiac membrane action potential from muscle contraction by displacing $\mathrm{Ca}^{+2}$ from cell surface binding sites. Thus, the noncompetitive inhibition of $\mathrm{Ca}^{+2}$ binding observed in our studies may reflect a unique membrane interaction of this trivalent cation.

Inhibition of calcium binding by potential antiarrhythmic and anesthetic agents

The results of experiments designed to measure the ability of a series of structural analogues of DL-propranolol to inhibit the calcium binding activity

Table 2. Inhibition of calcium binding to rat heart plasma membrane by antiarrhythmic and anesthetic agents*

\begin{tabular}{llcc}
\hline & & \\
& & \\
\hline
\end{tabular}

* Calcium binding activity was measured as described in Methods. Inhibition was competitive (C) or non-competitive (N-C) 
of the plasma membrane preparation are presented in Table 2. The results are organized in an attempt to facilitate comparisons of the effects of a related group of drug structures, differing by substitutions at a single position. The quaternary nitrogen derivative of propranolol, UM 272, is much less inhibitory than propranolol. However, UM 282, which differs from UM 272 by a phenyl group substitution, is more inhibitory than propranolol. The results of studies with compounds listed in Series II, demonstrate that a potent competitive inhibition of calcium binding can be achieved with a quaternary amine when the phenoxyl group is substituted with a phenyl group or iodine. Relatively less inhibition was produced by the methyl or hydrogen substituted analogues. The results of compounds listed in series III demonstrate that a tertiary substituted nitrogen atom (UM 329) is equivalent to a quaternary substituted nitrogen atom (UM 301) when calcium inhibition activities are compared. A nitrogen atom with a lower degree of substitution will produce less inhibition.

The local anesthetic dibucaine and the antiarrhythmic agent quinidine behaved similar to the majority of the experimental drug structures. Carbamylcholine, an analog of acetylcholine, exhibited almost 10 times more inhibitory activity than cholinc. Ouabain, a cardiac glycoside inhibitor of the $\mathrm{Na}^{+} \mathrm{K}^{+}$ATPase, was relatively ineffective.

\section{DISCUSSION}

Equilibrium dialysis was used to determine the parameters of calcium binding to the rat heart plasma membrane preparation. Only one calcium binding site was detectcd $\left(K_{d}=265 \mu \mathrm{M}, \quad B_{\max }=65 \mathrm{nmoles} / \mathrm{mg}\right.$ protein). A survey of the scientific literature reveals a broad diversity of calcium binding activities among plasma membranc preparations from a wide varicty of animal tissues. The presence of only one calcium binding site was detected by Madeira and Carvalho [8] with rabbit skclctal muscle $\left(K_{d}=40 \mu \mathrm{M}\right.$, $B_{\max }=40 \mathrm{nmoles} / \mathrm{mg}$ ) and by Schlatz and Marinetti [33] with rat liver $\left(K_{d}=200 \mu \mathrm{M}\right)$. The presence of two calcium binding sitcs was detceted by Madeira and Antunes-Madeira [34] with sheep brain $\left(K_{d}=0.87 \mu \mathrm{M}, 74 \mu \mathrm{M}\right)$, by Shami et al. [35] with guinca pig placenta $\left(K_{d}=31 \mu \mathrm{M}, 1.1 \mathrm{mM}\right)$. and by Hemminki [36] with rat brain $\left(K_{d}=360 \mu \mathrm{M}\right.$, $27 \mathrm{mM}$ ). It must be assumed that the measurement of these unique calcium binding activitics is dependent upon the particular method of plasma membrane isolation and the range of calcium ion concentration that is selected.

A simple comparison of calcium binding affinities and binding capacities does not provide a sufficient basis for an assessment of the expected biological properties of plasma membrane preparations. Therefore, an extensive series of inhibition measurements, using metal ions and experimental membrane active agents, were performed to more fully characterize the calcium binding properties of the rat heart plasma membrane preparation. A wide variety of monovalent metal ions exhibited 10-100-fold less inhibition potency than divalent metal ions as determined by a comparison of competitive inhibition $K_{i}$ values. Furthermore, the range of $K_{i}$ values found for the divalent metal ions was very similar to the calcium $K_{d}$ value. These results suggest the absence of a large number of specific metal ion binding sites which can select a divalent cation by its characteristic ionic radius and electron charge density. Instead, the plasma membrane apparently contains a large region of anionic sites which can discriminate the net ionic charge of a cation, in this case exhibiting a greater preference for divalent cations than for sodium or potassium ions. This property may be important in the cardiac plasma membrane since this membrane is directly involved in regulating the flux of metal ions in the cardiac conduction-contraction cycle [1, 2].

Seeman [3] and Papahadjopoulos [37] have recently presented extensive reviews of scientific literature which support the concept that plasma membrane phospholipids serve as the site of metal ion and local anesthetic agent binding. Furthermore, the displacement of metal ions bound to acidic phospholipids is believed to be the primary mechanism of anesthetic action. The studies described in this communication demonstrate that a variety of structural analogues of DL-propranolol can displace calcium from binding sites on rat cardiac plasma membranes. The inhibitory potencies of the compounds tested were estimated by determining inhibition constants $\left(K_{i}\right)$. Specifically, a 50 per cent inhibition would be expected to occur if these agents were present at a concentration equal to twice the competitive $K_{l}$ value when the calcium concentration is equal to the dissociation constant $\left(K_{d}\right)$. Electrophilic and (or) hydrophobic substituents on the phenoxy ring system or on the isopropylamine group generally increased the inhibitory activity of the compound. Diamino substituted agents were morc potent inhibitors than related monoamino structures. This may explain the ability of carbamylcholine to displace calcium at one-tenth the concentration required for choline. Tertiary amines (UM 329) were slightly more potent inhibitors of calcium binding than the related primary and secondary amincs (UM 312, UM 284). Howcver, there was no significant difference between the effects of related tertiary and quaternary amines (UM 329. UM 301). Shectz and Singer [38] have speculated that quaternary amines cannot readily permeate through a cell mambrane to reach the cytoplasmic side. Thus, the quaternary amine agents, and possibly the other less substituted isomers, may be acting to competitively inhibit the binding of calcium to external sites on the plasma membranc. The potent inhibition of calcium binding caused by UM 282 may be due to its unique amphipathic structure. This agent possesses two aromatic groups separated by a quaternary substituted nitrogen atom. Sheetz and Singer [38] have proposed that the hydrophobic end of a local anesthetic agent penetrates into the nonpolar lipid bilayer region of the membrane. Thus. UM 282 would possess two hydrophobic groups for an enhanced interaction with the lipid bilayer of the membrane. This association would permit the cationic amino group to interact with anionic sites at hydrophilic regions of the membrane. This 
compound provides an interesting prototype for the design of future membrane active agents.

The concentrations required to produce a significant inhibition of calcium binding to the plasma membrane preparation fall within the approximate range of $100-400 \mu \mathrm{M}$. These concentrations may be higher than would be required to achieve inhibition in vivo especially since the local concentration of a drug at membrane binding sites may be much higher than that in free circulation $[8,39,40]$. In fact, Kniffen et al. [8] have observed that there is a poor correlation between the plasma concentration and the therapeutic effectiveness of quaternary ammonium antiarrhythmic agents, because myocardial tissue appears to concentrate these compounds. Thus, while the concentrations required to achieve inhibition of calcium binding as determined in these studies may serve as a relative indication of the inhibition potency, the results do not indicate the therapeutic dose which would be required to elicit this effect in vivo.

We have shown that DL-propranolol, UM 272, and UM 424 have widely differing abilities to competitively inhibit the calcium binding activity of the plasma membrane preparation. B. R. Lucchesi and coworkers have presented a series of communications $[6-8]$ which describe the antiarrhythmic properties of these compounds. When DL-propranolol, UM 272, and UM 424 were used to reverse ouabain-induced arrhythmia in live dogs, an average dose of $6.1,3.0$, and $4.6 \mathrm{mg}$ drug $/ \mathrm{kg}$ body weight (respectively) was required to restore and maintain a normal sinus rhythm for a period of at least $30 \mathrm{~min}$. In comparison, the corresponding $K_{i}$ values for inhibition of calcium binding, as determined in the present study, are 108, 795, and $115 \mu \mathrm{M}$. Thus, the most potent antiarrhythmic agent (UM 272) has the least ability to inhibit calcium binding to cardiac plasma membrane. This low activity for competitive inhibition may be another desirable characteristic of this agent, in addition to the previously described [7] lack of anesthetic and $\beta$-adrenergic blocking activities. The relative inability of an antiarrhythmic agent to inhibit calcium binding would avoid the undesirable side-effects (depression of myocardial contractility) encountered with some antiarrhythmic agents [39].

\section{REFERENCES}

1. G. A. Langer, Fedn Proc. 35, 1274 (1976)

2. G. A. Langer, Circ. Res., Suppl. 3, 35, 91 (1974)

3. P. Seeman, Pharm. Rev. 24, 583 (1972).

4. B. G. Covino, New Eng. J. Med. 286, 1035 (1972).

5. A. M. Watanabe and H. R. Besch, J. Pharm. exp. Ther. 191, 241 (1974).

6. B. R. Lucchesi, L. S. Whitsitt, and N. L. Brown, Can. J. Physiol. Pharmac. 44. 543 (1966).
7. D. P. Schuster, B. R. Lucchesi, N. L. Nobel, M. N. Mimnaugh, R. E. Counsell, and F. J. Kniffen. J. Pharm. exp. Ther. 184, 213 (1973).

8. F. J. Kniffen, S. Winokur, R. E. Counsell, and B. R. Lucchesi, J. Pharm. exp. Ther. 196, 420 (1976).

9. V. M. C. Madeira and A. P. Carvalho, Biochim. biophys. Acta 266, 670 (1972).

10. A. P. Carvalho, V. M. C. Madeira, and M. C. Antunes-Madeira, Biachim. biophys. Acta 234, 210 (1971).

11. S. L. Rosenthal, P. M. Edelman, and I. L. Schwartz. Biochim. biophys. Acta 109, 512 (1965).

12. S. I. Zacks, H. Vandenburg. and M. F. Sheff, $I$ Histochem. Cytochem. 21, 895 (1973).

13. H. Vandenburg, M. F. Sheff, and S. I. Zacks, J. memb. Biol. 17, 1 (1974).

14. O. H. Lowry, N. J. Rosebrough, A. L. Farr, and R. J. Randall, J. biol. Chem. 193, 265 (1951).

15. G. M. Richards, Analyt. Biochem. 57, 369 (1974).

16. F. H. Kirkpatrick, S. E. Gordesky, and G. V. Marinetti, Biochim biophys. Acta 345, 154 (1974).

17. J. Folch, M. Lees, and G. H. Sloane-Stanley, J. biol. Chem. 226, 497 (1957).

18. P. A. Weinhold and C. A. Villee, Biochim biophys. Acta 106. 540 (1965).

19. T. F. Slater and D. N. Planterose, Biochem. J. 74, 591 (1960).

20. L. A. Heppel and R. J. H. Hilmore, Meth. Enzymol. 2, 547 (1955).

21. H. Sanui, Anulyt. Biochem. 60, 489 (1974).

22. I. M. Klotz, F. M. Walker, and R. B. Pivan, J. Am. chem. Soc. 68, 1486 (1946).

23. M. Dixon and E. C. Webb, Enzymes, 2nd Edn, p. 315. Academic Press, New York (1964).

24. M. J. Karnovsky, J. Cell Biol. 35, 213 (1967).

25. J. H. Luft. J. Biophys. Biochem. Cytol. 9, 409, (1961).

26. J. Venable and R. Coggeshall, J. Cell Biol. 25, 407 (1965).

27. P. V. Sulakhe, G. I. Drummond and D. C. Ng, $J$. biol. Chem. 248, 4158 (1973).

28. S. Harigaya and A. Schwartz, Circ. Res. 25, 781 (1969).

29. G. Inesi, Ann. Rev. Biophys. Bioeng. 1, 191 (1972).

30. C. Hui, M. Drummond, and G. I. Drummond, Archs Biochem. Biophys. 173, 415 (1976).

31. D. B. McNamara, J. N. Singh, and N. S. Dhalla, J. Biochem. 76, 603 (1974).

32. H. Reuter, Circ. Res. 34, 599 (1974).

33. L. Shlatz and G. V. Marinetti, Biochim. biophys. Acta 290. $70(1972)$.

34. V. M. C. Madeira and M. C. Antunes-Madeira, Biochim. biophys. Acta 323, 396 (1973).

35. Y. Shami, H. H. Messer, and D. H. Copp, Biochim. biophys. Acta 339, 323 (1974).

36. K. Hemminki. Biochim. biophys, Acta 363, 202 (1974).

37. D. Papahadjopoulos, Biochim. biophys. Acta 265, 169 (1972).

38. M. P. Sheetz and S. J. Singer, Proc. natn. Acad. Sci. U.S.A. 71, 4457 (1974).

39. E. Shinebourne, R. White, and J. Hamer, Circ. Res. 24, 835 (1969).

40. J. A. C. Harrow and N. S. Dhalla, Biochem Pharmac. 25, 897 (1976).

41. J. D. Owen, Biochim. biophys. Acta 451, 321 (1976). 